\title{
Patient-Ventilator Interaction With Noninvasive Proportional Assist Ventilation in Subjects With COPD
}

\author{
Jianheng Zhang, Qun Luo, and Rongchang Chen
}

\begin{abstract}
BACKGROUND: To investigate patient-ventilator interaction during different levels of noninvasive proportional assist ventilation (PAV) compared with noninvasive pressure support ventilation (PSV). METHODS: Fifteen subjects with severe COPD and hypercapnia were consecutively recruited. After the baseline assessment of unassisted spontaneous breathing, 3 levels of ventilatory support were applied. The proportional assist (PA) and pressure support (PS) levels were set by subject comfort. PA - , PS - or PA +, PS + were set at $25 \%$ more or less of PA or PS (PA- $=75 \%$ PA, $\mathrm{PA}+=125 \%$ PA, PS $-=75 \%$ PS, PS $+=125 \%$ PS). Each level lasted at least $20 \mathrm{~min}$. To demonstrate the patient-ventilator interaction, the neural respiratory drive, respiratory muscle effort, flow signal, and airway pressure were simultaneously monitored. RESULTS: The expiratory cycle delay (time between the termination of the diaphragm electromyogram $\left[\mathbf{E M G}_{\mathrm{di}}\right]$ signal and the end of the inspiratory flow) progressively increased with increasing assist level in both modes. However, compared with PSV, the expiratory cycle delay was significantly longer in each assist level during noninvasive PAV. The runaway phenomenon was observed in PA+. The time between the peak EMG $_{\mathrm{di}}$ signal and the maximum value of the flow signal and the time difference between the peak $\mathbf{E M G}_{\mathrm{di}}$ signal and the maximum value of inspiratory pressure were significantly increased with the increasing assist level of PAV. CONCLUSIONS: The expiratory cycle delay of noninvasive PAV was significantly longer than that of noninvasive PSV in the subjects with COPD with respiratory failure. During the levels of $\mathrm{PAV}$, the lag time between neural respiratory drive and airway pressurization was significantly increased and the "runaway" phenomenon may be observed. (ClinicalTrials.gov registration NCT01782768.) Key words: pressure support ventilation; proportional assist ventilation; noninvasive ventilation; neural respiratory drive; asynchrony events; patient-ventilator interaction. [Respir Care 2020;65(1):45-52. (c) 2020 Daedalus Enterprises]
\end{abstract}

\section{Introduction}

Proportional assist ventilation (PAV) has been used with noninvasive ventilation (NIV) for almost 20 years. Some

Drs Zhang, Luo, and Chen are affiliated with the State Key Laboratory of Respiratory Disease, National Clinical Research Center for Respiratory Disease, Guangzhou Institute of Respiratory Health, Guangzhou, China and with The First Affiliated Hospital of Guangzhou Medical University, Guangzhou, China.

The study was funded by State Key Laboratory of Respiratory Disease, National Clinical Research Center for Respiratory Disease, Guangzhou Institute of Respiratory Health, Guangzhou, China.

The authors have disclosed no conflicts of interest.

Supplementary material related to this paper is available at http:// www.rcjournal.com. studies showed that NIV-PAV enhanced subject comfort and synchrony, which could enhance the success rate. ${ }^{1,2}$ In our previous research, neuroventilatory coupling of subjects with COPD was not remarkably improved by welltolerated assist levels of noninvasive PAV compared with noninvasive pressure support ventilation (PSV). ${ }^{3} \mathrm{Neu}-$ roventilatory coupling (the ratio of ventilation to neural respiratory drive) is associated with dyspnea and comfort of the subjects with COPD. ${ }^{4}$ Increasing levels of noninvasive PAV may enhance comfort in patients with COPD because of an improvement in neuroventilatory coupling.

Correspondence: Rongchang Chen MD, 151 Yanjiang Road, Guangzhou, Guangdong Province 510120 China. E-mail: Chenrc123@qq.com.

DOI: $10.4187 /$ respcare. 06430 
However, neuroventilatory coupling may not be the only factor related to patient comfort because the patient-ventilator interaction may also play a role. There is research that, in NIV-PSV, a $25 \%$ increase in a well-tolerated inspiratory pressure causes more asynchrony events and overdistention. ${ }^{5}$ Furthermore, a computer model indicated that expiratory asynchrony may be an inherent shortcoming of PAV. ${ }^{6}$ Therefore, we hypothesized that a $25 \%$ increase in a well-tolerated level of NIV-PAV would also cause more asynchrony events and overdistention, which would then decrease comfort scores. The present study was undertaken to examine the patient-ventilator interaction during different levels of NIV-PAV compared with NIV-PSV.

\section{Methods}

The investigative protocol was approved by the institutional ethics committee of Chinese State Key Laboratory of Respiratory Disease, and informed consents were obtained from all the subjects who participated. The work was performed in the First Affiliated Hospital of Guangzhou Medical University. Our study was registered in Clinicaltrials.gov (NCT01782768) on April 29, 2013.

\section{Subjects}

Fifteen subjects with severe COPD and hypercapnia were consecutively recruited. The diagnosis of COPD was made according to the Global Initiative for Chronic Obstructive Lung Disease guideline. ${ }^{7}$ All the subjects were on longterm oxygen therapy $(2 \mathrm{~L} / \mathrm{min})$ and received NIV after admission. The criteria to initiate NIV were as follows: (1) patients with COPD and respiratory acidosis $\left(\mathrm{P}_{\mathrm{aCO}_{2}}>\right.$ $45 \mathrm{~mm} \mathrm{Hg}$ ); and (2) severe dyspnea with clinical signs suggestive of respiratory muscle fatigue, increased work of breathing, or both, such as the use of respiratory accessory muscles, paradoxical motion of the abdomen, or retraction of the intercostal spaces. ${ }^{7}$ Measurements were performed on the subjects 3-5 d after admission. The basic information of the subjects is presented in Table 1. Respiratory status was measured at the time of recovery. Arterial blood gas data were measured during spontaneous breathing with oxygen therapy $(2 \mathrm{~L} / \mathrm{min})$ at the time of study. The exclusion criteria included the following: severe cardiovascular disease, pneumonia, neuromuscular and chest-wall deformity, respiratory arrest, cardiovascular instability (hypotension, arrhythmias, myocardial infarction), change in mental status or patients who were uncooperative, high risk of aspiration, viscous or copious secretions, recent facial or gastroesophageal surgery, craniofacial trauma, fixed nasopharyngeal abnormalities, burns, and extreme obesity.

\section{QUICK LOOK}

\section{Current knowledge}

Proportional assist ventilation (PAV) has been implemented in noninvasive ventilation (NIV) for almost 20 years. Some studies have shown that NIV-PAV could enhance patient comfort and synchrony, which would enhance the success rate. In our previous research, the dyspnea of subjects with COPD could not be remarkably relieved by NIV-PAV.

\section{What this paper contributes to our knowledge}

In the present study, the expiratory cycle delay of NIV PAV was significantly longer than that of NIV pressure support ventilation in the subjects with COPD and with respiratory failure. During PAV, the pressure and flow supply lagged behind the neural respiratory drive demand of the subjects. At the high assist level, the lag behind between the airway pressure supply and the neural respiratory drive was significantly increased, and the runaway phenomenon was observed. The delay between the neural drive and the positive pressure supply might be a new type of asynchrony that would decrease patient comfort during NIV.

\section{Measurements}

To demonstrate the interaction between subject effort and ventilator response, the neural drive, respiratory muscle effort, flow signal, and airway pressure were simultaneously monitored. The flow signal was obtained from a heated pneumotachograph (Erie, Fleish No 1 Pneumotachograph, Lausanne, Switzerland) connected to a differential pressure transducer (ML141, ADInstruments, Melbourne, Australia). The pneumotachograph was inserted between the face mask and the plateau valve (Respironics, Pittsburgh, Pennsylvania) of the NIV circuit. Tidal volume $\left(\mathrm{V}_{\mathrm{T}}\right)$ was calculated by numerical integration of the flow signal. The minute ventilation was calculated as the product of $\mathrm{V}_{\mathrm{T}}$ and breathing frequency.

Pressure at the airway opening was measured with a pressure transducer (HY Ruishibo Medical Technology, Guangzhou, China) connected to one port of the face mask. Changes in esophageal pressure and gastric pressure were recorded by using the balloon-catheter technique. The 2 catheters were connected to the pressure transducer (HY Ruishibo). The design and positioning of the balloon catheter followed the American Thoracic Society/European Respiratory Society Statement on Respiratory Muscle Testing. ${ }^{8}$ The correct positioning of the esophageal balloon measurement was tested by using the occlusion method 
Table 1. Baseline Data of the Subjects With COPD and Hypercapnia

\begin{tabular}{lc}
\hline \hline \multicolumn{1}{c}{ Baseline Data } & Results \\
\hline Age, $\mathrm{y}$ & $67.5 \pm 10.1$ \\
$\mathrm{BMI}, \mathrm{kg} / \mathrm{m}^{2}$ & $21.4 \pm 4.1$ \\
$\mathrm{P}_{\mathrm{aO}_{2}}, \mathrm{~mm} \mathrm{Hg}$ & $83.7 \pm 16.7$ \\
$\mathrm{P}_{\mathrm{aCO}}, \mathrm{mm} \mathrm{Hg}$ & $60.3 \pm 9.7$ \\
$\mathrm{pH}$ & $7.33 \pm 0.04$ \\
$\mathrm{FEV}_{1}, \mathrm{~L}$ & $0.61 \pm 0.15$ \\
$\mathrm{FEV}_{1}$ predicted \% & $22 \pm 5$ \\
$\mathrm{FEV}_{1} / \mathrm{FVC} \%$ & $35 \pm 8$ \\
$\mathrm{FVC}, \mathrm{L}$ & $1.83 \pm 0.56$ \\
$\mathrm{FVC}_{\text {predicted } \%}$ & $53 \pm 16$ \\
$\mathrm{RMS}_{\text {max }}, \mu \mathrm{V}$ & $176.8 \pm 58.6$ \\
\hline Data are presented as mean $\pm \mathrm{SD}$. & \\
$\mathrm{BMI}=$ body mass index & \\
$\mathrm{RMS}_{\max }=$ largest value of the root mean square obtained from maximum maneuvers \\
\hline
\end{tabular}

while the subject was breathing through a mouthpiece. ${ }^{8} \mathrm{~A}$ multi-pair esophageal electrode catheter with 10 coils, which provided 5 pairs of electrodes, was used to obtain the diaphragm electromyogram $\left(\mathrm{EMG}_{\mathrm{di}}\right)$. The electrode design, positioning, and signal processing were performed as described by Jolley et $\mathrm{al}^{9}$ and Luo et al. ${ }^{10}$

\section{Ventilatory Settings}

All the subjects wore a face mask, fitted to the appropriate size, during the experiment. Both PSV and PAV were delivered noninvasively by the same ventilator (BiPAP Vision, Respironics). The ventilator circuit was equipped with a plateau valve (Respironics, Pennsylvania, Pittsburgh) to prevent $\mathrm{CO}_{2}$ rebreathing. The "runaway" method was used to set resistance (R) and elastance (E), as described by Porta et $\mathrm{al}^{11}$ and Younes. ${ }^{12}$ Before protocol initiation, the proportional assist (PA) and pressure support (PS) levels were assessed separately according to the subjects' comfort. Oxygen administration (5 L/min) was continuously delivered throughout ventilation, with $\mathrm{S}_{\mathrm{pO}_{2}}$ maintained at $>98 \%$. All the details of the setting can be found in the online supplementary materials (see the supplementary materials at http://www.rcjournal.com).

\section{Experimental Procedures}

The subjects were studied in the afternoon while they were in a semirecumbent position. After the application of topical anesthesia (10\% xylocaine), the subjects were asked to swallow 2 balloon-tipped catheters and the multipair esophageal electrode catheter through the nose into the correct position.
The protocol was a single-blind, randomized, crossover trial. During the first measurement period, signals of unassisted, stable, spontaneous breathing ( $\sim 5 \mathrm{~min})$ were collected as baseline data. After collection of this information, the subjects were randomly assigned to receive either PAV or PSV. We then titrated the original pressures (PA or PS) set for patient comfort to a $25 \%$ increase or to reduced levels for both $\mathrm{PA}$ and $\mathrm{PS}(\mathrm{PA}-=75 \% \mathrm{PA}$, $\mathrm{PA}+=25 \%$ increase of the baseline assist level [PA], $\mathrm{PS}-=75 \% \mathrm{PS}, \mathrm{PS}+=25 \%$ increase of the baseline inspiratory pressure [PS]). Thus, for each mode, 3 levels of support were applied $(\mathrm{PA}-, \mathrm{PA}, \mathrm{PA}+$; and $\mathrm{PS}-, \mathrm{PS}$, PS + ). A default level of $4 \mathrm{~cm} \mathrm{H}_{2} \mathrm{O}$ of expiratory positive airway pressure was applied to all the subjects. During the experiment, each level lasted at least 20 min until breathing was stabilized. Another period of spontaneous breathing followed the first stage of ventilation (washout period). When the magnitude of esophageal pressure returned to baseline, the other mode was started. All the raw signals were recorded, and the last 15 min of the stable computerstored data of each level were calculated and analyzed. Mean values were used for subsequent statistic analysis. At each period, the subjects scored their comfort with a visual analog scale, which ranged from 0 (worst) to 10 (best). The meaning of the visual analog scale and the questions were interpreted to the subject before the experiment. The physicians asked the subjects to rate how they felt at each assist level, and the subjects used this scaled rating to express their feelings. Leaks were monitored by the display of the ventilator and the computer during the procedure. When a leak was observed, the mask was carefully adjusted.

\section{Data Analysis}

The patient-ventilator interaction between the 2 types of noninvasive ventilator modes was considered as the primary outcome of this study. The inspiratory trigger delay was measured as the time difference between the beginning of the increase in the $\mathrm{EMG}_{\mathrm{di}}$ signal and the beginning of the ventilator inspiratory flow. The expiratory cycle delay was measured as the time course between the termination of the $\mathrm{EMG}_{\mathrm{di}}$ and the end of inspiratory flow during mechanical ventilation. By detecting the waveform of the $\mathrm{EMG}_{\mathrm{di}}$, the signal and airway pressure, 3 main types of asynchronies were quantified according to previously published definitions:13,14 (1) ineffective efforts, (2) auto-triggering, and (3) double triggering. Of note, double triggering was defined as one neural inspiration that triggers 2 breath cycles. The asynchrony index was defined as the number of asynchrony events divided by the total breathing frequency.

To further investigate the patient-ventilator interaction, the time course between the peak point of the $E M G_{d i}$ and the maximum value of flow signal and the time difference between maximum $\mathrm{EMG}_{\mathrm{di}}$ and maximum value of inspira- 
tory pressure were also measured. The air leak was calculated as the (inspiratory $\mathrm{V}_{\mathrm{T}}-$ the expiratory $\mathrm{V}_{\mathrm{T}}$ ) $\times$ the breathing frequency. The data of "runaway" in PA+ was selected to analyze. The $\mathrm{V}_{\mathrm{T}}$ was calculated by numerical integration of the flow signal.

\section{Statistical Analysis}

The results were expressed as mean $\pm \mathrm{SD}$. Differences of the physiologic data between each assisted level (PA-, PA, PA+; and PS -, PS, PS +) were evaluated by repeated measures analysis of variance, with Least significance difference test post hoc analysis for multiple comparisons. Differences of the visual analog scale scores between each assisted level were assessed with a Friedman test for multiple related samples. $P<.05$ was considered significant. Statistical analyses were performed by using SPSS 17.0 (SPSS, Chicago, Illinois).

\section{Results}

All the subjects well tolerated noninvasive PSV and PAV. The mean \pm SD value of the most-tolerated PAV assist level was $73 \pm 11 \%$. The comfort score during PS was significantly higher than that of PA. During PAV, the highest score was obtained at the PA level (mean $\pm \mathrm{SD}$, PA $5.9 \pm 0.8$ vs PA $-3.7 \pm 0.9, P<.001$; and PA vs $\mathrm{PA}+, 4.7 \pm 0.7, P<.001)$. There was no significant difference in air leak among the 3 levels of PSV (mean \pm $\mathrm{SD}, \mathrm{PS}-1.21 \pm 0.51 \mathrm{~L} / \mathrm{min}$; PS $1.44 \pm 0.64 \mathrm{~L} / \mathrm{min}$; PS+ $1.53 \pm 0.53 \mathrm{~L} / \mathrm{min}$ ). The air leak was significantly higher during $\mathrm{PA}+$, most likely related to the occurrence of the runaway phenomenon (mean $\pm \mathrm{SD}, \mathrm{PA}-1.25 \pm 0.57 \mathrm{~L} / \mathrm{min}$; PA $1.37 \pm 0.60 \mathrm{~L} / \mathrm{min} ; \mathrm{PA}+2.63 \pm 2.31 \mathrm{~L} / \mathrm{min} \mathrm{PA}-$ vs PA+, $P=.001 ;$ PA vs PA,$+ P=.002)$.

\section{Patient-Ventilator Interaction}

As shown in Figure 1, there was no significant difference in the inspiratory trigger delay with any settings between PAV and PSV. As shown in Figure 2, the expiratory cycle delay was progressively increased with increasing assist levels in both modes. However, in comparison with PSV, the expiratory cycle delay was significantly longer in each assist level during PAV $(P<.001)$. The runaway phenomenon was observed in $\mathrm{PA}+$, with an asynchrony index of $2.9 \pm 2.5$. The expiratory cycle delay of PA+ was remarkably increased among the 3 levels of PAV $(\mathrm{PA}+$ vs PA $[P<.001]$. and $\mathrm{PA}+\mathrm{vs} \mathrm{PA}-[P<.001])$. Typical asynchrony events (ineffective efforts, auto-triggering, double triggering) were not observed at any level of PAV. All the details are presented in Table 2.

As illustrated in Table 3 and Figure 3, the time course between the peak point of the $\mathrm{EMG}_{\mathrm{di}}$ signal and the max-

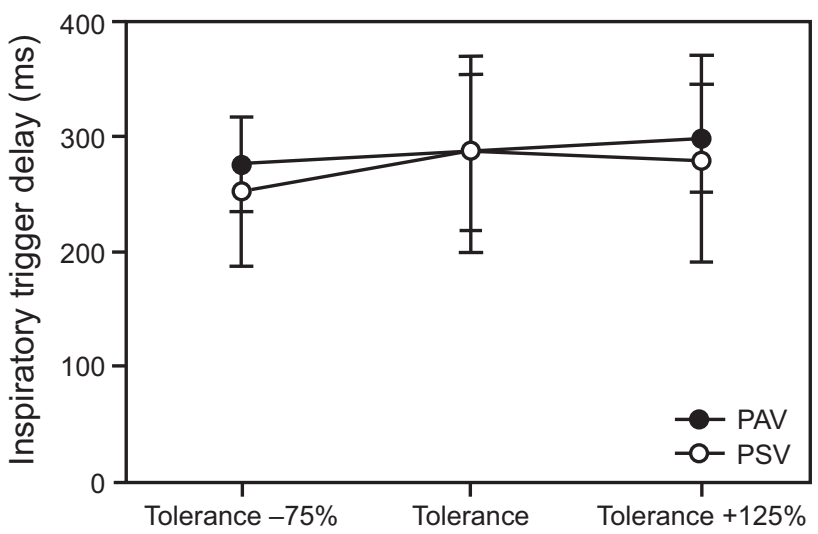

Fig. 1. Inspiratory trigger delay in 3 levels of proportional assist ventilation (PAV) and pressure support ventilation (PSV). Tolerance $=$ highest assisted level or inspiratory pressure set by subject tolerance.

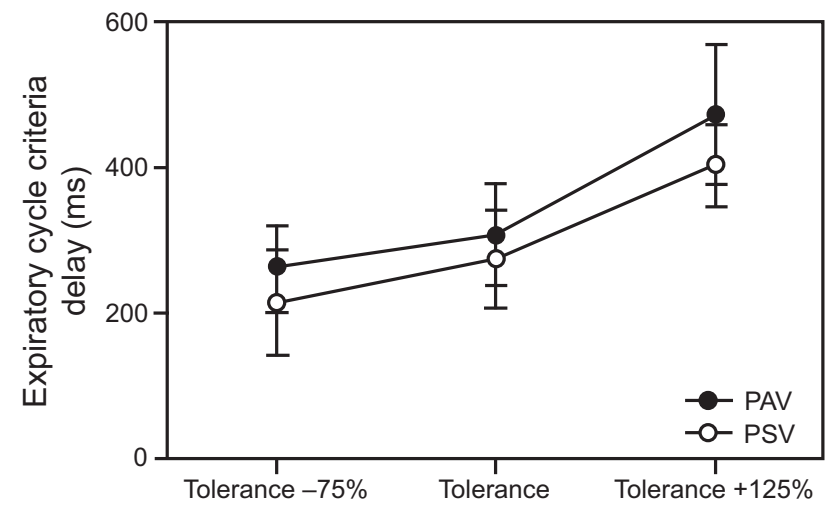

Fig. 2. Expiratory cycle delay in 3 levels of proportional assist ventilation (PAV) and pressure support ventilation (PSV). Tolerance $=$ highest assisted level or inspiratory pressure set by subject tolerance.

imum flow signal was significantly increased with increasing levels of PAV, which suggested that the inspiratory flow supply lagged behind the neural respiratory drive of the subjects. Similarly, the time difference between the peak of the $\mathrm{EMG}_{\mathrm{di}}$ signal and the maximum inspiratory pressure value was also significantly increased during all levels of PAV compared with PSV, which indicated that airway pressurization also lagged behind the neural respiratory drive of the subjects. The peak point of the $\mathrm{EMG}_{\mathrm{di}}$ signal and the maximum flow signal of PSV was significantly shorter than that of PAV at all assist levels. When the maximum value of the $\mathrm{EMG}_{\mathrm{di}}$ signal was achieved, the preset inspiratory pressure of the ventilator was already achieved (Fig 4). The time difference between $\mathrm{EMG}_{\mathrm{di}}$ peak and the maximum value of inspiratory pressure was considered as zero during PSV. Further details are presented in the online supplementary materials (see the supplementary materials at http://www.rcjournal.com). 
Table 2. Patient-Ventilator Interaction With Each of the 3 Levels of the 2 Modes: PA-, PA, PA+, PS-, PS, PS+

\begin{tabular}{lccl}
\hline \hline & $\begin{array}{c}\text { Inspiratory Trigger } \\
\text { Delay }(\mathrm{ms})\end{array}$ & $\begin{array}{c}\text { Expiratory Cycle } \\
\text { Delay }(\mathrm{ms})\end{array}$ & $P$ \\
\hline PA- & $276 \pm 41$ & $264 \pm 56$ & \\
PA & $285 \pm 82$ & $307 \pm 69$ & \\
PA+ & $299 \pm 47$ & $471 \pm 95$ & $<.001 \S \mathbb{I}$ \\
PS- & $254 \pm 64$ & $215 \pm 72$ & $=.046^{*}$ \\
PS & $287 \pm 68$ & $275 \pm 66$ & $=.014 \ddagger$ \\
PS + & $281 \pm 90$ & $404 \pm 57$ & $<.001 \Phi \S,=.007 \dagger$
\end{tabular}

Data are presented as mean $\pm \mathrm{SD}$

$* P<.05, \dagger P<.01$ with analysis for $\mathrm{PS}-$ vs $\mathrm{PA}-$, PS vs PA, PS + vs PA+

$\ddagger P<.05, \S P<.01$ with analysis of variance for PS - vs PS or PS - vs PS + , PA - vs PA

or $\mathrm{PA}-\mathrm{vs} \mathrm{PA}+$.

II $P<.01$ with analysis of variance for $\mathrm{PS}$ vs $\mathrm{PS}+$, PA vs PA+.

$\mathrm{PA}-=75 \%$ proportional assist

$\mathrm{PA}=$ proportional assist; the highest assist level set by subject tolerance

$\mathrm{PA}+=125 \%$ proportional assist

PS $-=75 \%$ pressure support

$\mathrm{PS}=$ pressure support; the highest inspiratory positive airway pressure set by subject tolerance $\mathrm{PS}+=125 \%$ pressure support

Table 3. Patient-Ventilator Interaction in Each of the 3 Levels of the 2 Modes: PA-, PA, PA+, PS -, PS, PS +

\begin{tabular}{|c|c|c|}
\hline $\begin{array}{l}\text { Assist } \\
\text { Level }\end{array}$ & $\begin{array}{c}\text { Time Difference Between the Diaphragm } \\
\text { Electromyogram Peak and the Maximum } \\
\text { Value of Inspiratory Pressure (ms) }\end{array}$ & $P$ \\
\hline $\mathrm{PA}-$ & $327 \pm 87$ & \\
\hline PA & $406 \pm 85$ & $=.005 \dagger$ \\
\hline $\mathrm{PA}+$ & $544 \pm 151$ & $<.001 \ddagger \S$ \\
\hline PS- & 0 & \\
\hline PS & 0 & \\
\hline $\mathrm{PS}+$ & 0 & \\
\hline \multicolumn{3}{|c|}{$\begin{array}{l}\text { Data are mean } \pm \mathrm{SD} \text {. } \\
\dagger P<.01 \text { with analysis of variance for PA- vs PA or PA- vs PA }+. \\
\ddagger P<.01, \S P<.01 \text { with analysis of variance for PA vs PA }+. \\
\mathrm{PA}-=75 \% \text { proportional assist } \\
\mathrm{PA}=\text { proportional assist; the highest assist level set by subject tolerance } \\
\mathrm{PA}+=125 \% \text { proportional assist } \\
\mathrm{PS}-=75 \% \text { pressure support } \\
\mathrm{PS}=\text { pressure support; the highest inspiratory positive airway pressure set by subject tolerance } \\
\mathrm{PS}+=125 \% \text { pressure support }\end{array}$} \\
\hline
\end{tabular}

\section{Discussion}

The main findings of our study were as follows: (1) increasing PAV levels increased the delay between the neural respiratory drive and airway pressurization during NIV; furthermore, at high assist levels, the expiratory cycle delay was significantly increased and the runaway occurred; and (2) an increasing PSV assist level would increase the expiratory cycle delay; however, the expiratory cycle delay and the delay between the neural respiratory drive and airway pressurization in NIV were significantly shorter in PSV than PAV.

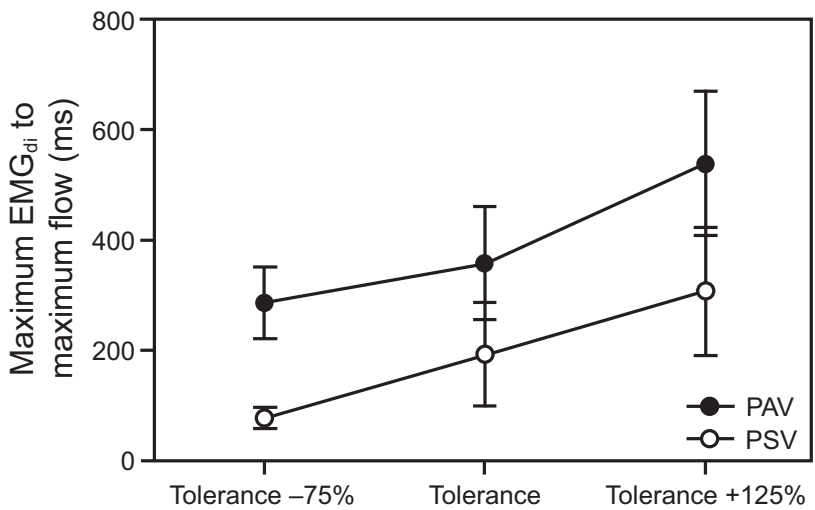

Fig. 3. The time course between peak point of diaphragm EMG $\left(E M G_{\mathrm{di}}\right)$ and maximum value of flow signal in 3 levels of proportional assist ventilation (PAV) and pressure support ventilation (PSV). Tolerance $=$ highest assisted level or inspiratory pressure set by subject tolerance.

The impaired neuroventilatory coupling of the subject with COPD is associated with higher inspiratory work and dyspnea. ${ }^{9}$ It can be significantly improved by using NIV. ${ }^{3}$ In the present study, the subjects were ventilated by using the same ventilator, type of interface, and circuit. The comfort score was highly correlated with dyspnea secondary to neuroventilatory coupling, the respiratory muscle load, and patient-ventilator interaction. . $^{3,4,13,15}$ As a result, the comfort score could be improved by improving this variable. At a high PAV level $(\mathrm{PA}+)$, the neuroventilatory coupling and $\mathrm{V}_{\mathrm{T}}$ were significantly increased. The respiratory muscle load was remarkably reduced (see the supplementary materials at http://www.rcjournal.com). However, the comfort score was lower than that of PA. It may be related to the runaway phenomenon and asynchrony in $\mathrm{PA}+$. The runaway phenomenon may contribute to asynchrony and overdistention, which decrease comfort scores. ${ }^{12}$

Furthermore, the time course between the airway pressurization and the neural respiratory drive was remarkably longer in PAV compared with PSV. In PA+, this time course was increased. When the neural respiratory drive, represented by the $\mathrm{EMG}_{\mathrm{di}}$ signal, reached its maximum value, the airway pressure was just increasing (Fig 4). When peak inspiratory pressure was attained, the neural respiratory drive was significantly decreased. The expiratory cycle delay was consistently greater in PAV, especially during high levels of assist. Patient-ventilator asynchrony is related to a poor comfort score during ventilation. ${ }^{5,16} \mathrm{We}$ speculated that the lag time in airway pressurization and the neural respiratory drive might be a new type of asynchrony. The decreased comfort score during PA + may be related to asynchrony, despite the improvement in neuroventilatory coupling. The expiratory cycle delay may be related to the control system delay of 


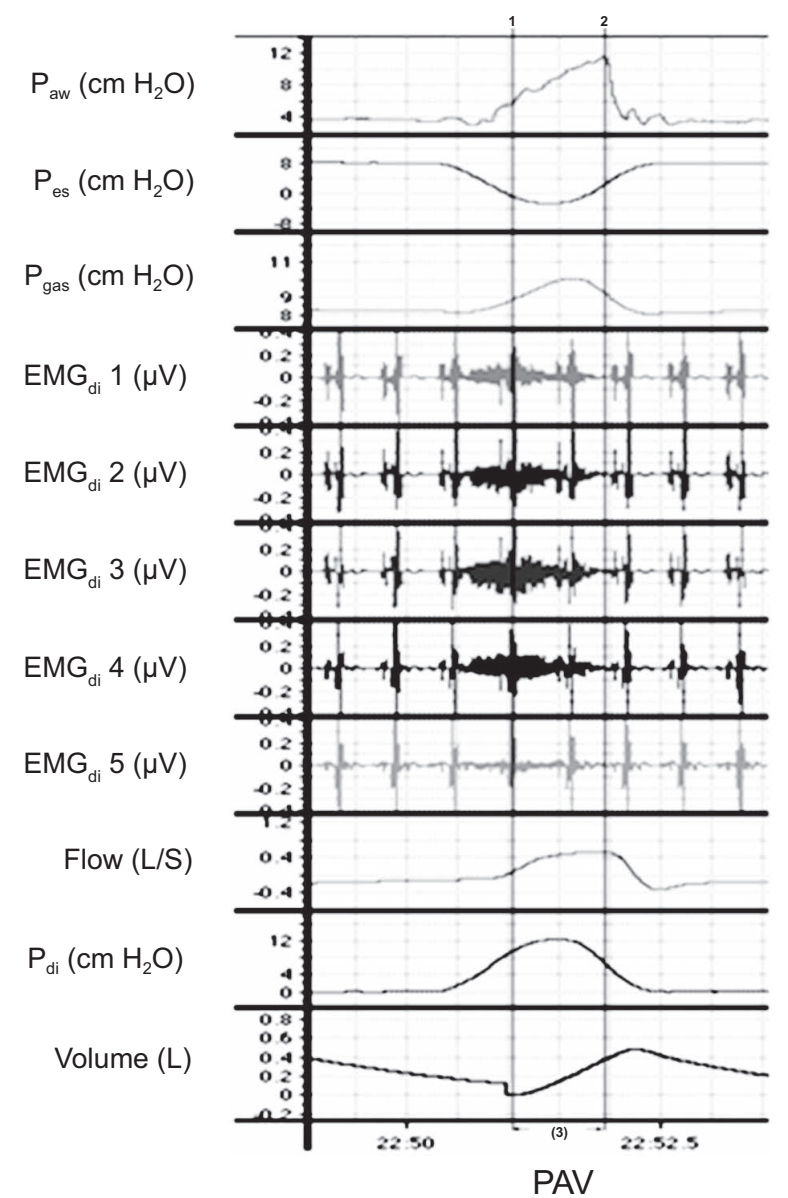

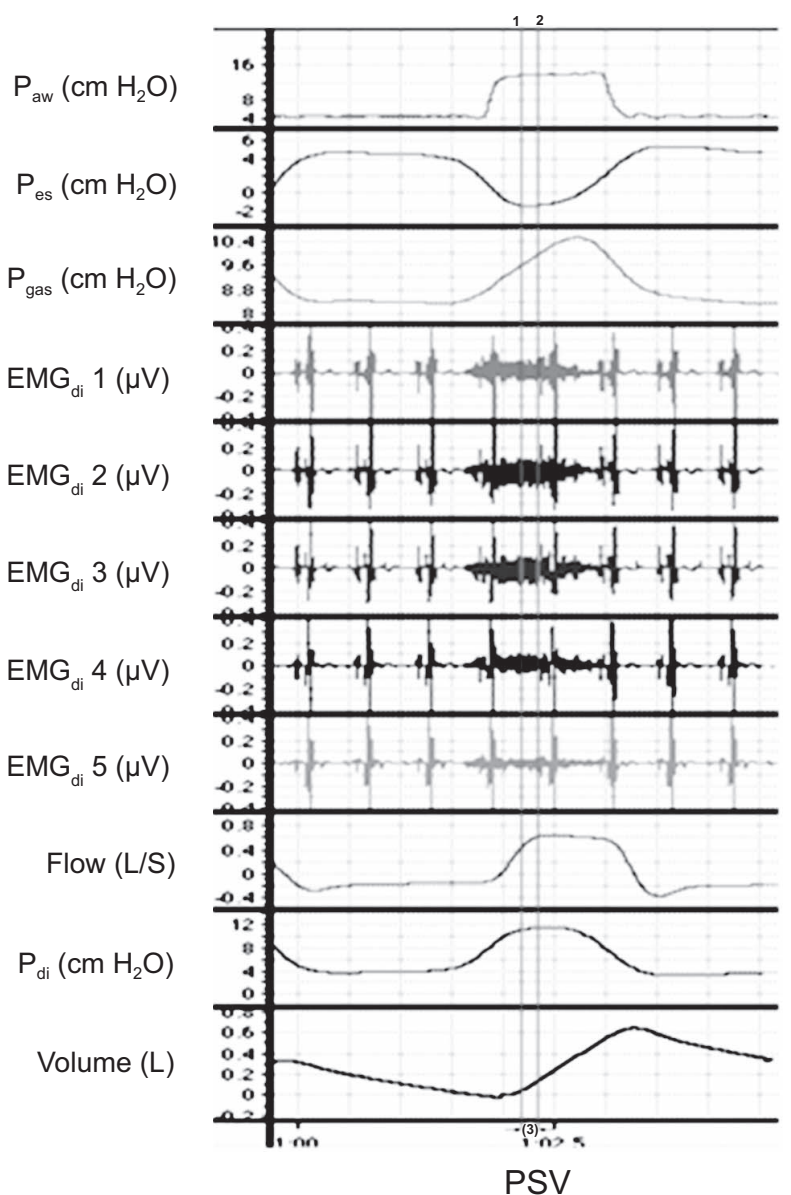

Fig. 4. Comparison of the lag behind of the airway pressure supply and neural respiratory drive between noninvasive proportional assist ventilation (PAV) and pressure support ventilation (PSV). $\mathrm{P}_{\mathrm{aw}}=$ airway pressure; $\mathrm{P}_{\mathrm{es}}=$ esophageal pressure; $\mathrm{P}_{\mathrm{ga}}=$ gastric pressure; $E M G_{d i}=$ diaphragm electromyogram; $P_{\mathrm{di}}=$ transdiaphragmatic pressure; Line $1=E M G_{\mathrm{di}}$ maximum; Line $2=$ maximum flow; Line $3=$ time between maximum $E M G_{d i}$ and maximum flow and $P_{a w}$.

the PAV ventilator. ${ }^{6}$ The lag time between $\mathrm{EMG}_{\mathrm{di}}$ activity and the initiation of ventilator support may also be associated with the delay of the PAV ventilated control system. There may be electronic delay, mechanical delay, and/or software control delay between the neural respiratory drive input and ventilator output. The development of a faster ventilator control system in PAV may reduce expiratory asynchrony and the time lag between $\mathrm{EMG}_{\mathrm{di}}$ activity and the initiation of ventilator support but could not get rid of the asynchrony. Furthermore, leakage is inevitable in NIV; the runaway phenomenon could not be got rid of too. ${ }^{12}$

In PS + (125\% PS), a remarkable expiratory cycle delay reflected a similar condition as PAV. However, the expiratory cycle delay was significantly shorter in PS and PScompared with PAV. When the maximum $\mathrm{EMG}_{\mathrm{di}}$ signal was achieved, the preset airway pressure of the ventilator was already achieved in PSV (Fig 4). In the present study, the time difference between $\mathrm{EMG}_{\mathrm{di}}$ peak and the maximum value of inspiratory pressure was considered as zero during PSV, although the preset PS has no relationship with neural respiratory demand. The inspiratory flow could be increased more quickly than that of PAV. This may be related to the effective improvement of neuroventilatory coupling during PSV.

\section{Clinical Implication}

As reported previously, inspiratory work of breathing can be significantly relieved with a high assist level of PAV. ${ }^{17,18}$ In the present study, we found the runaway phenomenon during PA+. The expiratory cycle delay was progressively increased. Furthermore, the lag time between the airway pressurization and the neural respiratory drive was also increased. Although the patient-ventilator interaction was good in the baseline assist levels of PAV (PA) titrated to comfort, the improvement of neuroventilatory coupling and inspiratory work of breathing was not significant compared with spontaneous breathing. We speculated that PAV would not be suitable during NIV in patients with COPD and with hypercapnia. The success of 
NIV depends on patient acceptance and compliance, which are likely to be associated with ventilator synchrony ${ }^{19}$ and the improvement of the neuroventilatory coupling of COPD. ${ }^{3}$

The impaired neuroventilatory coupling during COPD exacerbation could be significantly improved by noninvasive PSV compared with noninvasive PAV. ${ }^{3}$ The baseline inspiratory pressures titrated to comfort could reduce asynchrony and relieve dyspnea during NIV. ${ }^{3,5}$ Although the inspiratory pressure is preset, regardless of the neural respiratory drive, the diaphragmatic electrical activity base optimization strategy may help to improve synchronization. ${ }^{20}$ Diaphragmatic electrical activity could be monitored by surface electrodes with the development of the noninvasive technique. ${ }^{21}$ The novel finding of the present study was that the delay between the neural respiratory drive and airway pressurization may be a new type of asynchrony that could decrease patient comfort during NIV. Besides the typical asynchrony events, the asynchrony between the neural respiratory drive and airway pressurization should be assessed during NIV.

\section{Limitations of the Study}

Subject Selection. Fifteen subjects were recruited for the study. The participant number was limited because the balloon-catheter technique and multi-pair esophageal electrode catheter could not be performed in a larger sample size. We followed the design of previous studies. ${ }^{22,23} \mathrm{How}-$ ever, the number of subjects in the present study was more than that in previous studies.22-24 Significant differences were observed in most of the primary outcomes.

Critique of the Method. In NIV, the runaway method might be the only way to set $\mathrm{R}$ and $\mathrm{E}$, as described by Porta et al ${ }^{11}$ and Younes. ${ }^{12}$ Although the "runaway" method was introduced 20 years ago, no new method was described to estimated $\mathrm{R}$ and $\mathrm{E}$ in noninvasive ventilation. PAV with load-adjustable gain factors $(\mathrm{PAV}+)$ is a mode of support in which the ventilator pressure is proportional to the instantaneous flow (flow assist) and volume (volume assist). ${ }^{12,25}$ Flow and volume assist are automatically adjusted so that they always represent constant fractions of $\mathrm{R}$ and $\mathrm{E}$ of the respiratory system, as measured by the ventilator software. ${ }^{25-27}$ In PAV with load-adjustable gain factors, the $\mathrm{R}$ and $\mathrm{E}$ of the respiratory system were estimated by the interrupter technique during invasive ventilation. ${ }^{25-27}$ As a result, PAV with load-adjustable gain factors could not be applied during NIV. The runaway method may be the appropriate method set R and E in the NIV. To avoid the frequent invasive measurement of placing arterial catheters for sampling arterial blood, arterial blood gas data were not obtained during ventilation. Varying levels of inspiratory pressure most likely would not significantly influence minute ventilation and arterial blood gas values during short-term ventilation. ${ }^{28,29}$ The patient-ventilator interaction was the primary outcome in the present study.

\section{Conclusions}

The expiratory cycle delay of noninvasive PAV was significantly longer than that of noninvasive PSV in the subjects with COPD and with respiratory failure. During PAV, the pressure and flow lagged behind the neural respiratory drive demand of the subjects. During high levels of assist, the lag time between airway pressurization and neural respiratory drive was significantly increased and the runaway was observed. The baseline NIV-PSV inspiratory pressure titrated for comfort provided good patient-ventilator interaction.

\section{REFERENCES}

1. Gay PC, Hess DR, Hill NS. Noninvasive proportional assist ventilation for acute respiratory insufficiency. Comparison with pressure support ventilation. Am J Respir Crit Care Med 2001;164(9):16061611.

2. Wysocki M, Richard JC, Meshaka P. Noninvasive proportional assist ventilation compared with noninvasive pressure support ventilation in hypercapnic acute respiratory failure. Crit Care Med 2002;30(2): 323-329.

3. Zhang J, Luo Q, Zhang H, Chen R. Effect of noninvasive proportional assist vs pressure support ventilation on neuroventilatory coupling in chronic obstructive pulmonary patients with hypercapnia. Intensive Care Med 2014;40(9):1390-1391.

4. O'Donnell DE, Banzett RB, Carrieri-Kohlman V, Casaburi R, Davenport PW, Gandevia SC, et al. Pathophysiology of dyspnea in chronic obstructive pulmonary disease: a roundtable. Proc Am Thorac Soc 2007;4(2):145-168.

5. Zhang J, Luo Q, Zhang H, Chen R. Physiological significance of well-tolerated inspiratory pressure to chronic obstructive pulmonary disease patient with hypercapnia during noninvasive pressure support ventilation. COPD 2016;13(6):734-740.

6. Du HL, Ohtsuji M, Shigeta M, Chao DC, Sasaki K, Usuda Y, Yamada Y. Expiratory asynchrony in proportional assist ventilation. Am J Respir Crit Care Med 2002;165(7):972-977.

7. Vogelmeier CF, Criner GJ, Martinez FJ, Anzueto A, Barnes PJ, Bourbeau J, et al. Global Strategy for the Diagnosis, Management, and Prevention of Chronic Obstructive Lung Disease 2017 Report. GOLD Executive Summary. Am J Respir Crit Care Med 2017;195(5): 557-582.

8. American Thoracic Society/European Respiratory Society Statement on respiratory muscle testing. Am J Respir Crit Care Med 2002; 166(4):518-624.

9. Jolley CJ, Luo YM, Steier J, Reilly C, Seymour J, Lunt A, et al. Neural respiratory drive in healthy subjects and in COPD. Eur Respir J 2009;33(2):289-297.

10. Luo YM, Moxham J, Polkey MI. Diaphragm electromyography using an oesophageal catheter: current concepts. Clin Sci (Lond) 2008; 115(8):233-244.

11. Porta R, Appendini L, Vitacca M, Bianchi L, Donner CF, Poggi R, Ambrosino N. Mask proportional assist vs pressure support ventilation in patients in clinically stable condition with chronic ventilatory failure. Chest 2002;122(2):479-488. 


\section{AsynChrony of NoninVASIVE PAV}

12. Younes M. Proportional assist ventilation, a new approach to ventilatory support. Theory. Am Rev Respir Dis 1992;145(1):114-120.

13. Thille AW, Rodriguez P, Cabello B, Lellouche F, Brochard L. Patient-ventilator asynchrony during assisted mechanical ventilation. Intensive Care Med 2006;32(10):1515-1522.

14. Piquilloud L, Vignaux L, Bialais E, Roeseler J, Sottiaux T, Laterre $\mathrm{PF}$, et al. Neurally adjusted ventilatory assist improves patient-ventilator interaction. Intensive Care Med 2011;37(2):263-271.

15. Schmidt M, Banzett RB, Raux M, Morélot-Panzini C, Dangers L, Similowski T, Demoule A. Unrecognized suffering in the ICU: addressing dyspnea in mechanically ventilated patients. Intensive Care Med 2014;40(1):1-10.

16. Longhini F, Pan C, Xie J, Cammarota G, Bruni A, Garofalo E, et al. New setting of neurally adjusted ventilatory assist for noninvasive ventilation by facial mask: a physiologic study. Crit Care 2017; 21(1): 170 .

17. Delaere S, Roeseler J, D'hoore W, Matte P, Reynaert M, Jolliet P, et al. Respiratory muscle workload in intubated, spontaneously breathing patients without COPD: pressure support vs proportional assist ventilation. Intensive Care Med 2003;29(6):949-954.

18. Wrigge H, Golisch W, Zinserling J, Sydow M, Almeling G, Burchardi $\mathrm{H}$. Proportional assist versus pressure support ventilation: effects on breathing pattern and respiratory work of patients with chronic obstructive pulmonary disease. Intensive Care Med 1999; 25(8):790-798.

19. Nava S, Ceriana P. Patient-ventilator interaction during noninvasive positive pressure ventilation. Respir Care Clin N Am 2005;11(2): 281-293.

20. Beloncle F, Piquilloud L, Rittayamai N, Sinderby C, Rozé H, Brochard L. A diaphragmatic electrical activity-based optimization strategy during pressure support ventilation improves synchronization but does not impact work of breathing. Crit Care 2017;21(1):21.

21. Murphy PB, Kumar A, Reilly C, Jolley C, Walterspacher S, Fedele F, et al. Neural respiratory drive as a physiological biomarker to monitor change during acute exacerbations of COPD. Thorax 2011; 66(7):602-608

22. Poggi R, Appendini L, Polese G, Colombo R, Donner CF, Rossi A. Noninvasive proportional assist ventilation and pressure support ventilation during arm elevation in patients with chronic respiratory failure. A preliminary, physiologic study. Respir Med 2006;100(6): 972-979.

23. Serra A, Polese G, Braggion C, Rossi A. Non-invasive proportional assist and pressure support ventilation in patients with cystic fibrosis and chronic respiratory failure. Thorax 2002;57(1):50-54.

24. Passam F, Hoing S, Prinianakis G, Siafakas N, Milic-Emili J, Georgopoulos D. Effect of different levels of pressure support and proportional assist ventilation on breathing pattern, work of breathing and gas exchange in mechanically ventilated hypercapnic COPD patients with acute respiratory failure. Respiration 2003;70(4):355361.

25. Xirouchaki N, Kondili E, Vaporidi K, Xirouchakis G, Klimathianaki M, Gavriilidis G, et al. Proportional assist ventilation with loadadjustable gain factors in critically ill patients: comparison with pressure support. Intensive Care Med 2008;34(11):2026-2034.

26. Younes M, Kun J, Masiowski B, Webster K, Roberts D. A method for noninvasive determination of inspiratory resistance during proportional assist ventilation. Am J Respir Crit Care Med 2001;163(4): 829-839.

27. Younes M, Webster K, Kun J, Roberts D, Masiowski B. A method for measuring passive elastance during proportional assist ventilation. Am J Respir Crit Care Med 2001;164(1):50-60.

28. Nava S, Bruschi C, Rubini F, Palo A, Iotti G, Braschi A. Respiratory response and inspiratory effort during pressure support ventilation in COPD patients. Intensive Care Med 1995;21(11):871-879.

29. Schmidt M, Kindler F, Cecchini J, Poitou T, Morawiec E, Persichini $\mathrm{R}$, et al. Neurally adjusted ventilatory assist and proportional assist ventilation both improve patient-ventilator interaction. Crit Care 2015; 19:56. 